\title{
A RELAÇÃO ENTRE LIDERANÇA E O ENGAJAMENTO DOS PROFISSIONAIS NO SEGMENTO DE SERVIÇOS DE ALIMENTAÇÃO EM BARES E RESTAURANTES (FOODSERVICE)
}

\author{
THE RELATIONSHIP BETWEEN LEADERSHIP AND THE ENGAGEMENT OF \\ PROFESSIONALS IN THE FOOD SERVICE SEGMENT IN BARS AND \\ RESTAURANTS (FOODSERVICE)
}

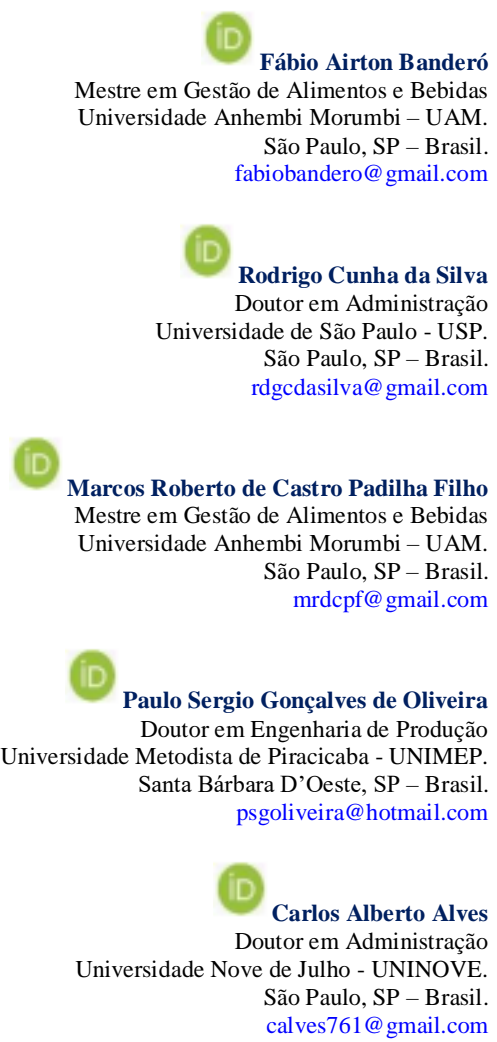

Resumo

O objetivo do artigo foi verificar a existência de relacionamento entre o tipo de liderança e o engajamento dos colaboradores com a organização. Para se atingir o objetivo foi efetuado um levantamento transversal, junto a profissionais do setor de alimentos e bebidas, ligados a área de bares e restaurantes na cidade de São Paulo, sendo coletadas 146 respostas válidas. Os dados foram analisados por meio da análise de variância (Anova), por meio do teste de Levene, para se verificar diferenças nas variâncias, de forma a se testar os dados demográficos, utilizou-se o teste $\mathrm{T}$, com nível de significância $<0,05$. Os resultados demonstram a importância da liderança empoderadora e diretiva em relação ao engajamento dos profissionais do setor Alimentos e Bebidas, na área de Bares e Restaurantes.

Palavras-Chave: Setor de alimentos e bebidas. Práticas de Recursos Humanos em bares e restaurantes. Liderança empoderadora. Liderança diretiva. Engajamento profissional.

\section{Abstract}

The paper aim was to verify the existence of a relationship between the type of leadership and the engagement of employees with the organization. To achieve the objective a transversal survey was carried out with professionals of the food and beverage sector, linked to the area of bars and restaurants in the city of São Paulo, being collected 146 valid answers. The data was analyzed using variance analysis (Anova), by means of the Levene test, to verify differences in variances, to test demographic data, the $\mathrm{T}$ test was used, with a significance level $<0.05$. The results demonstrate the importance of empowering and directive leadership in relation to the engagement of professionals in the Food and Beverage sector, in Bars and Restaurants.

Keywords: Food and beverage sector. Human Resource practices in bars and restaurants. Empowering leadership. Directive leadership. Professional engagement.

\section{Cite como}

American Psychological Association (APA)

Banderó, F. A., Silva, R. C., Padilha Filho, M. R. C., Oliveira, P. S. G., \& Alves, C. A. (2021, set./dez.). A relação entre liderança e o engajamento dos profissionais no segmento de serviços de alimentação em Bares e Restaurantes (foodservice). Revista de Gestão e Projetos (GeP), 12(3), 121-142. https://doi.org/10.5585/gep.v12i3.20641. 


\section{Introdução}

As organizações vêm passando por uma série de desafios nos últimos anos, devido a uma série de fatores, tais como o aumento da concorrência, as diversas crises que vem afetando praticamente todos os países no mundo, das quais pode se citar a pandemia da Covid-19, que provocou o fechamento de diversas empresas ao redor do mundo, levando os gestores a precisarem buscar alternativas cada vez mais criativas. Nesse contexto, a indústria de Turismo e Hospitalidade, da qual faz parte o setor de alimentos e bebidas, foi um dos mais afetados em todo o mundo, levando ao fechamento de diversas empresas, fazendo com que as que sobreviveram dependessem de soluções cada vez mais embasadas na melhoria da performance organizacional e na redução de custos.

\section{A performance organizacional} está frequentemente associada a vantagem competitiva, pois visa desenvolver mecanismos que criam uma melhora no desempenho de longo prazo, utilizando para isso a visão baseada em recursos, por meio da qual visa utilizar os conhecimentos existentes dentro da organização de forma a se criar um diferencial competitivo (Rezende Oliveira et al., 2017). Nesses tempos de incerteza os gestores precisam avaliar de uma forma não enviesada os riscos organizacionais, principalmente aqueles ligados ao processo de tomada de decisão de forma a minimizar os riscos e melhor a assertividade reduzindo dessa forma a incerteza (Moon, 2021).

O aumento da incerteza provocado pelas mudanças citadas anteriormente fez com que os pesquisadores se debruçassem sobre os conceitos de liderança e desempenho organizacionais, como uma forma de se lidar com os riscos, ganhando dessa forma significativa atenção nos últimos anos principalmente quando ligado ao comportamento empreendedor, já que o setor de alimentos, principalmente $\mathrm{o}$ ligado a bares e restaurantes é composto por pequenos empreendimentos, muitas vezes tendo o proprietário como o seu único gestor (Qadir \& Yeşiltaş, 2020). No entanto, cabe ressaltar que o conceito de liderança pode ser visto a partir de diversas abordagens o que leva a uma compreensão do que é uma liderança eficaz ou não, tornando o processo de interpretação e prática complexos (Schley et al., 2015).

Devido a necessidade cada vez maior dos bares e restaurantes atingirem níveis cada vez maiores de excelência, tendo como propósito melhorar a sua competitividade e, portanto, a sua 
Banderó, F. A., Silva, R. C., Padilha Filho, M. R. C., Oliveira, P. S. G., \& Alves, C. A. (2021, set./dez.). A relação entre liderança e o engajamento dos profissionais no segmento de serviços de alimentação em Bares e Restaurantes (foodservice)

capacidade de sobrevivência as práticas de gestão de recursos humanos, tornamse cada vez mais necessárias. No entanto, cabe ressaltar que o sucesso de uma equipe, depende em grande parte da atuação da liderança, pois só obterá resultados se o líder souber conduzir de forma correta os seus subordinados. Dessa forma, cabe ressaltar que o engajamento dos colaboradores é um estratégia gerencial que visa o alinhamento do interesse dos membros da organização com os objetivos organizacionais (Rees et al., 2013).

Cabe aqui ressaltarmos que a importância do engajamento dos profissionais se dá pelo fato do compromisso dos indivíduos com a organização se visto com uma questão crítica, já que esse pode variar de acordo como uma série de fatores, sofrendo em grande parte uma forte influência da liderança, fazendo com que as organizações passassem a prestar atenção no papel desempenhado pelo líder (Rego et al., 2016). Devido a essa visão de que as organizações precisam de líderes eficazes, os quais tem um grande impacto na motivação dos funcionários, por meio do estabelecimento do compromisso entre eles e a organização, pode-se inferir que existe uma correlação entre a liderança e o compromisso organizacional (Qadir \& Yeşiltaş, 2020).

Com base neste contexto, este estudo adotou a seguinte pergunta problema: Como se dá a relação entre o tipo de liderança e o aumento engajamento dos colaboradores com a organização? Para tanto, o objetivo da pesquisa foi verificar a existência de relacionamento entre o tipo de liderança e o engajamento dos colaboradores com a organização.

O estudo se justifica devido a importância que o setor de alimentos e bebidas tem para o país, sendo um dos maiores empregadores de mão de obra na atualidade, além de muitas vezes ser a primeira oportunidade de trabalho da maioria das pessoas (Abrasel, 2021). Além disso, o setor de bares e restaurantes em sua maioria é constituído de pequenas empresas, as quais empregam boa parte da população econômica ativa no Brasil, segundo dados do Caged (Cadastro Geral de Empregados e Desempregados), sendo também um dos que mais sofreu durante a pandemia da Covid-19 (CAGED, 2021). 


\section{Referencial teórico}

Essa seção tem por meta desenvolver o referencial teórico do estudo, permitindo se entender melhor como se encontram definidos os conceitos e as tipologias de liderança e de engajamento.

\subsection{Perspectivas sobre o conceito de liderança}

Na atualidade de nossa sociedade devido ao uma série de fatores, a incerteza se faz presente nas mais diversas situações, demandando dos gestores uma forma de lidar de uma maneira não enviesada com os riscos organizacionais, pois as decisões tendem a envolver uma grande quantidade de riscos, o que pode levar a decisões não corretas de acordo com o contexto organizacional (Moon, 2021).

Esse aumento do nível de incerteza levou os pesquisadores a se debruçarem em cima do conceito de liderança, como uma forma de lidar com esses riscos organizacionais, fazendo com que ganhasse significativa atenção nos últimos anos principalmente quando associada ao comportamento empreendedor, principalmente no que tange a pequenas empresas, o que é uma realidade da maioria dos bares $\mathrm{e}$ restaurantes (Qadir \& Yeşiltaş, 2020).
O conceito de liderança pode ser visto em distintas abordagens. Estas contribuem para a ideia que de não existe um abordagem única para a compreensão do que é uma liderança eficaz ou não, o que torna o seu processo de interpretação e prática complexa e, igualmente, um objeto de busca pelos praticantes (Schley et al., 2015).

Essa multiplicidade de significados reflete de certa forma uma certa desarmonia a respeito de que maneira é possível identificar os líderes e também o processo de liderança, por esse motivo um dos precursores do movimento Burns utilizou o termo liderança transformacional de modo a relacionar a liderança com base na moralidade e na motivação, o que levou outros pesquisadores a discutir diferentes definições de liderança transformacional (Qadir \& Yeşiltaş, 2020).

Esse movimento motivou Benedetti Chammas e Da Costa Hernandes (2019) a estudar a influência das lideranças transformacionais $\mathrm{e}$ instrumentais com relação à performance individual dos colaboradores em startups brasileiras, o que levou a um melhor entendimento empírico da influência da liderança em relação ao desempenho dos funcionários, 
Banderó, F. A., Silva, R. C., Padilha Filho, M. R. C., Oliveira, P. S. G., \& Alves, C. A. (2021, set./dez.). A relação entre liderança e o engajamento dos profissionais no segmento de serviços de alimentação em Bares e Restaurantes (foodservice)

o que pode demonstrar a forma como os diferentes estilos de liderança influenciam de forma direta no desempenho dos colaboradores.

De toda forma, de acordo com Barreto et al. (2013), um líder tem a capacidade de influenciar pessoas para o alcance das metas, sendo elas formais conferidas pela empresa, ou informais, definidas como aquela exercida no grupo, sem o cargo formal. Devido a essa capacidade de influência, houve uma motivação geral no sentido de buscar o entendimento da forma como os líderes influenciavam os seus liderados. Sendo as primeiras pesquisas sobre liderança eram classificadas como baseada na Teoria dos Traços de Personalidade (Granez et al., 2016). Tiveram suas origens nos anos 1920, distinguindo o líder dos liderados por suas características de personalidade (físicas ou habilidades cognitivas).

Em seguida, surgiram as teorias comportamentais com o foco para a identificação do melhor estilo de liderar e se diferenciava da teoria dos traços por oferecer uma lista de estilos ou comportamento ao invés de uma lista de traços pessoais. Em vez de traços, a liderança passou a ser investigada para a identificação dos padrões de comportamento adotados pelos líderes è suas funções (Junior, 2014).

Durante o século XX houve uma proliferação no que se refere as definições a respeito do termo de liderança, porém a espinha dorsal que sustente todas essas definições em dúvida é fato de que a maioria delas tem por base a influência exercida pelo líder em relação aos seus líderes (Benedetti Chammas \& da Costa Hernandez, 2019).

Já durante a metade do século $\mathrm{XX}$, começam a aparecer as teorias contingenciais as quais se desenvolveram a partir da perspectiva de que os estilos de liderança podem ser eficazes em algumas circunstâncias e em outras não, sendo por isso importante sob essa ótica os líderes optarem por qual deveriam exercer a fim de se adaptar as mais diversas situações

$\mathrm{Na}$ segunda metade do século $\mathrm{XX}$, surgem as abordagens contingenciais que se desenvolveram a partir de observações de que os estilos de liderança podem ser eficazes para umas circunstâncias e não para outras, às quais os líderes deveriam se adaptar. Por modo dessa perspectiva o modo adequado de liderar irá depender da interação entre as situações a que os líderes são expostos e o grau de ajustamento de seu estilo a essas situações, na medida em que 
quando as situações variam, os requisitos da liderança também irão variar (Dallabona et al., 2019; Nunes \& Pinheiro, 2010).

Não obstante, a influência do líder será maior se ele mantiver relações respeitosas com seus liderados, isto é, que os levem a gostar dele e a nele confiar (Rodrigues et al., 2013). Por outro lado, quando o líder especifica clara e detalhadamente como a tarefa deve ser feita, ou quando ela é clara e estruturada, haverá maior chance de influenciar as ações dos grupos que lidera (Leite et al., 2013).

Corroborando com as teorias discutidas anteriormente que se focalizam nas características do líder, as teorias processuais preocupam-se com os processos de liderança, isto é, na maneira em que as relações entre líderes e liderados é estabelecida (Benedetti Chammas \& da Costa Hernandez, 2019; Junior, 2014). Outra das principais teorias processuais é a da liderança transformacional, introduzida por Burns (1978) e, em seguida, aprofundada por (Bass et al., 2003). Em relação a proposta de Bass a respeito das lideranças transformadoras, transacional e laissez-faire (Benedetti Chammas \& da Costa Hernandez, 2019).
De acordo com esse modelo, a liderança transacional associa-se a uma relação de reciprocidade entre líderes e liderados. Os líderes transacionais esclarecem as metas e objetivos, organizam as tarefas e atividades em cooperação com seus funcionários, de modo a garantir que tais metas sejam de fato atingidas e oferecem recompensas (tais como remunerações e reconhecimentos), a partir dos resultados das avaliações de desempenho. Sob essa perspectiva, então, a habilidade de obter resultados mediante o planejamento e a organização de tarefas, segundo os limites das estruturas e processos organizacionais, é o que torna o líder eficaz (Benedetti Chammas \& da Costa Hernandez, 2019).

Da Silva e Dos-Reis (2016) afirmam que a liderança transformacional se baseia na busca do alinhamento dos liderados com a estratégia organizacional. Assim o líder tem o papel de trazer os liderados para o processo de validação do planejamento organizacional. A liderança transformacional situa-se no atual contexto das mudanças no ambiente de trabalho, como no fato das organizações serem menos hierárquicas, mais flexíveis e mais orientadas para o trabalho em equipe (Rodrigues, Ferreira \& Mourão, 
2013). Desta forma, a abordagem da liderança transformacional vem sendo amplamente utilizada para se abordar o fenômeno de liderança.

Por outro lado, a liderança transformacional, possui como finalidade vital o desenvolvimento de esforços para proporcionar um aumento na motivação, satisfação e desenvolvimento dos liderados, por meio principalmente da confiança e da facilitação e não pelo controle direto. Dessa forma o líder que adota uma postura transformacional visa promover uma visão de longo prazo, advindo o poder do líder da compreensão e da confiança, enquanto no modelo de liderança transacional a relação se baseia na hierarquia e na posição (Benedetti Chammas \& da Costa Hernandez, 2019).

A partir do século XXI, começam a surgir novas abordagens e proposições relativas ao desenvolvimento da liderança, fato que também despertou no setor de serviços alimentares, tais como bares e restaurantes um conscientização nesse sentido, já que percebeu-se a dificuldade que existe nessa área no sentido de se engajar os funcionários, representando dessa forma um grande desafio para a gestão de pessoas, tendo portanto a liderança como ponto central, já que o gestor de alimentos e bebidas é um dos principais responsáveis por colocar em prática as iniciativas relativas a gestão de pessoas nesse setor (Kraemer \& Aguiar, 2009).

A partir desse período um dos conceitos que ganhou grande destaque foi o de liderança participativa, a qual se refere a forma como os líderes proveem aos membros da organização a oportunidade de participar no processo de tomada de decisões, fazendo com que os colaboradores possuam influência no processo de decisão. A liderança participativa é diretamente relacionada ao conceito de empoderamento dos funcionários, sendo portanto utilizado de maneira similar, permitindo aos membros da organização compartilhar o poder, encorajando a produção de resultados por parte do funcionários (SangWoo Hahm, 2020).

Já o conceito de liderança criativa procura encorajar os colaboradores a atingirem o seu potencial criativo, fato primordial para se gerar diferencial competitivo nas organizações atuais, inclusive para os bares e restaurantes, criando dessa forma competências essenciais, no entanto cabe ressaltar que o líder não é necessariamente criativo, mas que procura influenciar a criatividade dos seus seguidores. A liderança criativa atinge um alto grau de 
inovação por meio principalmente da utilização das redes de relacionamento dos colaboradores, os quais compartilham capital humano por meio do compartilhamento de suas experiências pessoais, habilidades, conhecimento, obtenção de conhecimento (SangWoo Hahm, 2020).

Já a liderança delegada procura estabelecer um comportamento de suporte e comportamento diretivo do líder, sendo um estilo de liderança por meio do qual se procura estabelecer a cessão do poder para os liderados e não para os líderes. Dessa forma quando o líder delega uma tomada de decisão ou mesmo métodos de trabalho, ele direciona os membros da organização, os quais são obrigados a decidir de que maneira irão desenvolver as suas tarefas, fazendo dessa forma com que os membros se tornem comprometidos e espontâneos em seu trabalho, conferindo dessa forma confiança e capacidade aos trabalhadores, gerando autoeficácia (SangWoo Hahm, 2020).

Em relação a liderança parte-se do princípio que em situações onde às práticas de gestão de pessoas não consigam sustentar o engajamento, existe a necessidade da liderança empoderar e direcionar adequadamente o comportamento de sua equipe (R. C. da
Silva et al., 2015). Na seção a seguir, tratamos dos estudos contemporâneos sobre engajamento e liderança empreendedora e diretiva.

\subsection{Engajamento e a relação com a liderança empreendedora e diretiva}

$\mathrm{O}$ sucesso de uma equipe depende, em grande parte, da atuação da liderança, pois a equipe só terá bons resultados se o líder souber conduzir de forma correta seus subordinados. $\mathrm{O}$ aumento dos níveis de engajamento dos funcionários é o mais recente de uma longa linha de estratégias gerenciais, que visam o alinhamento dos interesses dos empregados com os objetivos organizacionais (Rees et al., 2013).

A importância do engajamento dos profissionais se dá pelo fato $\mathrm{o}$ compromisso dos indivíduos com as suas organizações passou a ser visto como uma questão crítica, já que esse pode variar de acordo com diversos fatores, sendo sofrendo em grande parte uma forte influência da liderança, como tem sido apontado em alguns casos, sendo por esse motivo uma das razões pelas quais as organizações se voltarem para o papel desempenhado pelo líder na busca por encontrar o otimismo organizacional (Rego et al., 2016). 
Banderó, F. A., Silva, R. C., Padilha Filho, M. R. C., Oliveira, P. S. G., \& Alves, C. A. (2021, set./dez.). A relação entre liderança e o engajamento dos profissionais no segmento de serviços de alimentação em Bares e Restaurantes (foodservice)

Por meio dessa visão torna-se visível de que todas as organizações precisam de líderes eficazes, os quais possam aumentar os índices de motivação dos funcionários, por meio do estabelecimento do compromisso entre eles e a organização. Não obstante alguns estudo levaram a conclusão de os líderes tem o potencial de afetar tanto o desempenho organizacional, quanto o comprometimento das equipes, por meio da inspiração de seus liderados, demonstrando existir uma correlação entre a liderança e o compromisso organizacional (Qadir \& Yeşiltaş, 2020).

O estudo de Sungu et al. (2019) veio a corroborar essas ideias, pois ao estudar 398 funcionários e seus supervisores, conseguiu estabelecer uma moderação entre compromisso ocupacional afetivo e a liderança transformacional, separadamente e de forma interativa, permitindo demonstrar uma forte associação entre desempenho do trabalho dos funcionários com um alto comprometimento ocupacional, com uma alta liderança desempenhada pelos supervisores.

Esses resultados se devem ao fato de um funcionário que possui alto grau de compromisso organizacional se identificar fortemente com os objetivos organizacionais, estabelecendo dessa forma um alinhamento entre os seus ideais e os da organização. O compromisso organizacional pode ser definido como afetivo, de continuidade e normativo, sendo definidos da seguinte forma: o compromisso afetivo, ocorre quando existe um apego psicológico entre o funcionário e a organização, o compromisso de continuidade ocorre quando existe uma intenção por parte do empregado em ficar na organização e o normativo se refere a uma percepção do empregado de que possui uma dívida com a organização e que portanto é mais vantajoso ficar (Mitonga-Monga, 2020).

Por esse motivo entende-se que o engajamento promove nos funcionários e equipes, uma sensação de vigor que se apresenta por meio de uma alta energia e resiliência mental, o que promove a dedicação e o envolvimento intenso nas tarefas propostas, desenvolvendo um senso de capacidade, além do entusiasmo promovido pelo desafio, gerando um envolvimento positivo (Knight et al., 2017).

O engajamento dos funcionários por meio desse entendimento gera uma contribuição dos colaboradores, já que possui um caráter direcionado ao cumprimento das metas organizacionais. Já Rees, Alfes e Gatenby (2013) chamam a atenção para a imersão e de presença 
no trabalho promovida pelo engajamento, devido principalmente a postura positiva dos colaboradores durante a realização dos trabalhos, por meio do estabelecimento de conexões significativas com os demais membros da organização. Dessa forma se faz possível a distinção de três facetas presentes no engajamento:

- Engajamento intelectual: quando os indivíduos estão absorvidos em seu trabalho e pensam em de melhorar seu desempenho no trabalho;

- Engajamento afetivo - quando os indivíduos sentem conexões emocionais positivas a sua experiência de trabalho;

- Engajamento social - quando os indivíduos conversam com colegas sobre melhorias que podem ser realizadas no trabalho.

Assim, pode-se entender que o comprometimento organizacional, também conhecimento como engajamento nas empresas torna-se um fator importante na gestão e na liderança de recursos humanos, afetando dessa maneira o desempenho e a competitividade da organização, além de impactar de maneira intensa os colaboradores, reforçando a crença de que o compromisso e a dedicação dos funcionários pode reduzir a flutuação e apoiar o desempenho humano na gestão de recursos, promovido pelas dimensões do comprometimento: afetivo, instrumental e normativo (P. L. da Silva et al., 2019; Miško et al., 2021).

Devido ao fato da liderança empoderadora (delegada) ter o potencial para o desenvolvimento do engajamento devido ao fato de que esse estilo de liderança favorece a cessão de poderes de decisão para os membros da organização, tendo os líderes o papel de direcionar os membros da organização, favorecendo a responsabilidade adicional, o que gera motivação intrínseca, foram formuladas as hipótese H1 e H2 (Park et al., 2019; SangWoo Hahm, 2020):

- H1- A liderança empoderadora está relacionada positivamente ao engajamento dos funcionários do setor de food service.

- H2- Existem diferenças na percepção da liderança empoderadora, conforme o perfil e expectativas do profissional na empresa.

Já a liderança diretiva envolve a orientação clara sobre quais e como serão realizadas as tarefas dos 
Banderó, F. A., Silva, R. C., Padilha Filho, M. R. C., Oliveira, P. S. G., \& Alves, C. A. (2021, set./dez.). A relação entre liderança e o engajamento dos profissionais no segmento de serviços de alimentação em Bares e Restaurantes (foodservice)

subordinados e que resultados são esperados destes. O comportamento diretivo provê estrutura psicológica aos subordinados: permite-lhes saber o que é esperado deles através de planejamento e coordenação do trabalho, apresentação de diretrizes específicas e esclarecimento de políticas e regras (Park et al., 2019).

Devido ao fato de a liderança diretiva estar relacionado ao fato de o líder fornecer as diretrizes para que o trabalho seja feito, deixando claro o que se espera de seus subordinados, além de monitor ativamente as atividades, fornecendo feedback constante aos seus liderados, parte-se do princípio de que haverá uma propensão maior ao engajamento dos profissionais, surgindo dessa forma as hipóteses H3, H4 e H5 desse estudo (Park et al., 2019; Qadir \& Yeşiltaş, 2020; SangWoo Hahm, 2020):

- H3- A liderança diretiva está relacionada positivamente ao engajamento dos funcionários do setor de food service.

- H4- Existem diferenças na percepção da liderança diretiva, conforme o perfil e expectativas do profissional na empresa.

- H5- Existem diferenças no grau de engajamento, conforme o perfil e expectativas do profissional na empresa.

\section{Procedimentos metodológicos}

$\mathrm{O}$ estudo adotou o método hipotético-dedutivo para a análise dos dados, pois tem por objetivo testar hipóteses relativas a um estudo das características sociais dos elementos da amostra estudada, de forma a se identificar os estilos de liderança e avaliar as relações existentes com o engajamento dos colaboradores no setor de bares e restaurantes na cidade de São Paulo (Creswell \& Clark, 2013; Kerlinger, 1988).

A pesquisa pode ser considerada descritiva, por meio da análise das características dos participantes, além de testes de diferença por meio da análise de variância (ANOVA), utilizando para isso o teste de Levene, que visa identificar a homogeneidade das variâncias (Jr et al., 2009; Pestana \& Gageiro, 2009, 2014).

Para a coleta dos dados foi utilizada uma pesquisa de levantamento do tipo transversal, tendo a coleta sido desenvolvida junto a um grupo de 146 profissionais do setor de alimentos e bebidas, ligados a área de bares e restaurantes (Babbie, 1999). Os dados foram coletados utilizando um 
formulário do Google forms, composto por 6 assertivas relativas à liderança empoderadora, 6 ligadas a liderança diretiva e 4 sobre o engajamento dos profissionais, cada uma variando de $1=$ Discordo Totalmente a 5=Concordo totalmente, por meio de uma escala de Likert.

Os resultados foram submetidos ao SPSS versão 22, onde foi desenvolvida a análise de variância (ANOVA), de forma se testar as hipóteses relativas ao estudo por meio do teste de Levene e análise dos dados demográficos por meio do Test $\mathrm{T}$

\section{Figura 1}

Faixa Etária x Gênero dos Respondentes

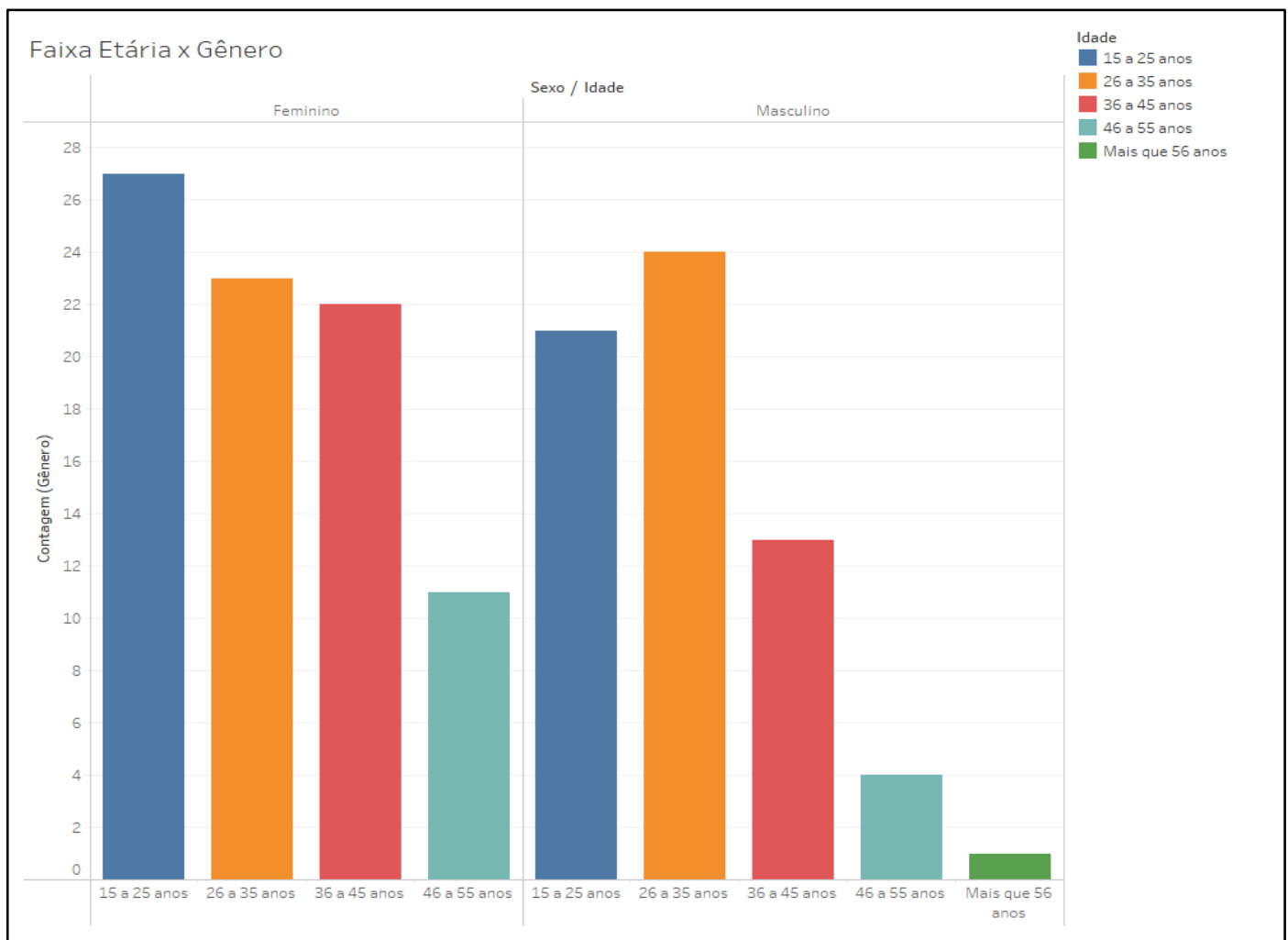

Fonte: Pesquisa, 2020.
(Malhotra \& Menezes, 2019; Pestana \& Gageiro, 2009). O próximo tópico visa apresentar as análises dos resultados encontrados na pesquisa, além de fazer a discussão.

\section{Análise dos resultados e discussão dos resultados}

De modo a se descrever a amostra da pesquisa, foi feita primeiramente a análise demográfica dos dados, iniciando-se por meio da Figura 1, onde é apresentada a frequência relativa dos respondentes de acordo com a faixa etária e o gênero. 
Banderó, F. A., Silva, R. C., Padilha Filho, M. R. C., Oliveira, P. S. G., \& Alves, C. A. (2021, set./dez.). A relação entre liderança e o engajamento dos profissionais no segmento de serviços de alimentação em Bares e Restaurantes (foodservice)

Por meio da Figura 1, pode-se observar que a amostra na faixa de 15 a 25 anos é composta por 27 pessoas do gênero feminino e 21 do gênero masculino, a faixa entre 26 a 35 anos possui 23 mulheres e 24 homens, a faixa entre 36 a 45 anos é composta por 22 pessoas do gênero feminino e 13 do gênero masculino, na faixa de 46 a 55 anos, temos 11 mulheres e 4 homens e em relação aos respondentes com mais de 56 anos, temos apenas 1 pessoa do gênero masculino.

A Figura 2 demonstra as expectativas dos respondentes da pesquisa em relação ao seu desenvolvimento no setor de alimentos e bebidas.

\section{Figura 2.}

Expectativas Profissionais dos Respondentes em Relação ao Setor de Alimentos e Bebidas

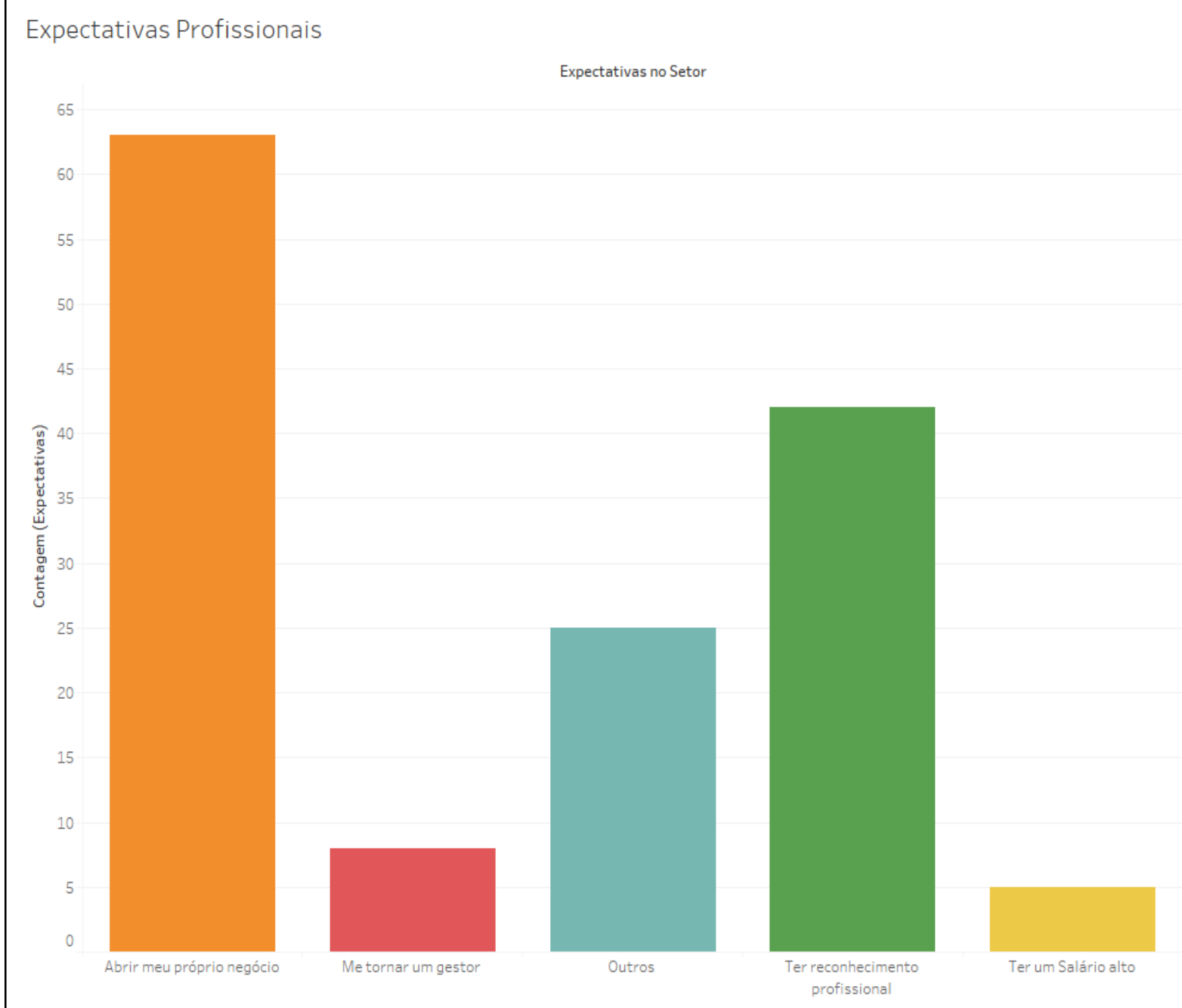

Fonte: Pesquisa, 2020. 
Em relação as expectativas dos respondentes quanto ao seu futuro profissional a grande maioria deles, 63 declararam que desejam "abrir o seu próprio negócio", enquanto 42 gostariam de "Ter reconhecimento profissional", 25 marcaram "outros", 8 declaram ter o desejo de setor gestor e 5 disseram que tem expectativa de perceber um salário alto.

\section{Figura 3.}

Função dos respondentes no Setor de Alimentos e Bebidas

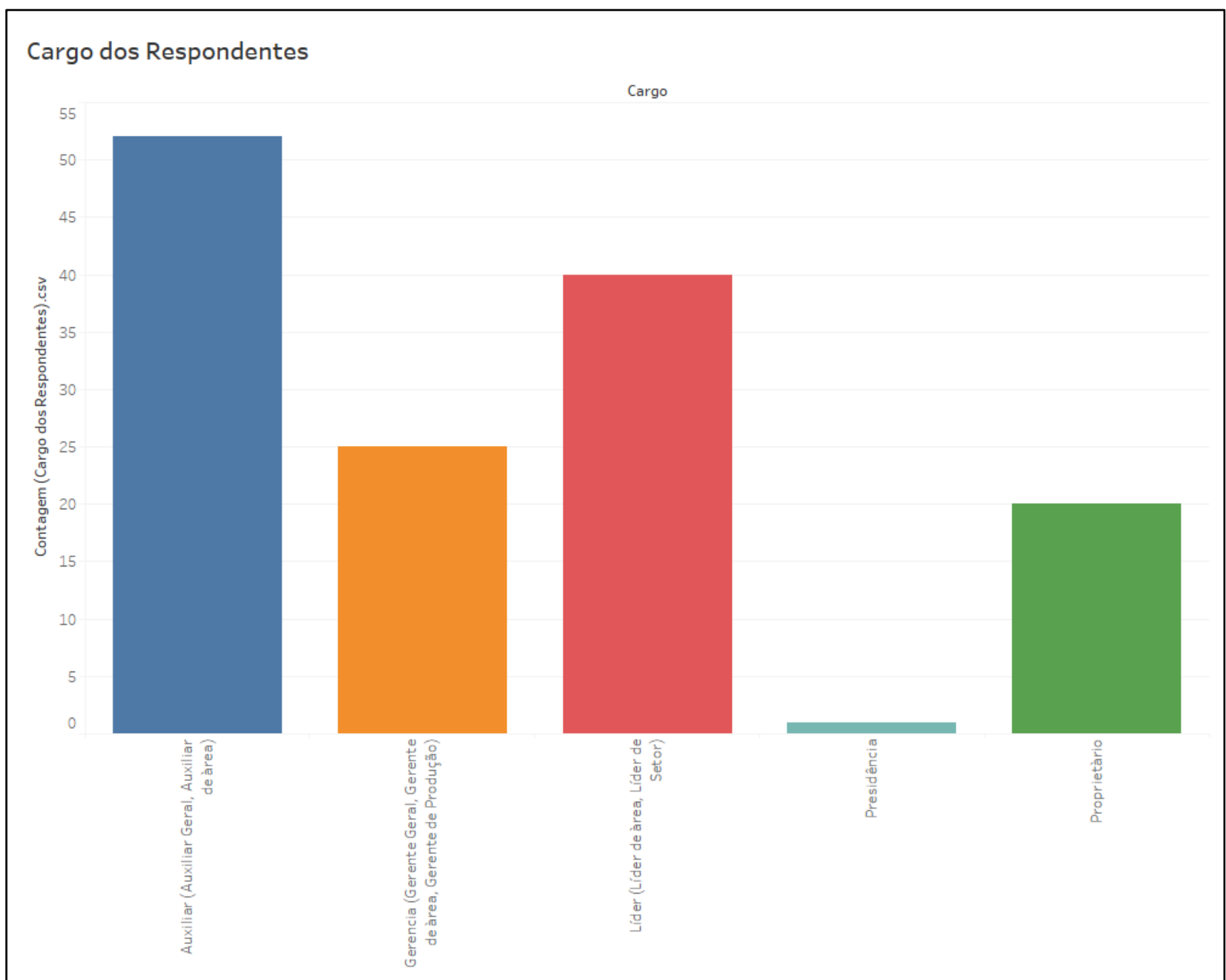

Fonte: Pesquisa, 2020.

Por meio da Figura 3, pode-se observar que a maioria dos respondentes se enquadram na função de Auxiliar (52), seguido por Líder (4), Gerente (25), Proprietário (20) e Presidente (1). Tendo sido realizada a análise descritiva dos dados, se passou aos testes de significância, para se testar as hipóteses do estudo.

Logo a seguir, os valores individuais de cada uma das assertivas 
Banderó, F. A., Silva, R. C., Padilha Filho, M. R. C., Oliveira, P. S. G., \& Alves, C. A. (2021, set./dez.). A relação entre liderança e o engajamento dos profissionais no segmento de serviços de alimentação em Bares e Restaurantes (foodservice)

do questionário são apresentados na

Tabela 1.

Tabela 1.

Médias e Desvios-Padrões das Assertivas Referentes à Engajamento, Liderança Empoderadora

\section{e Diretiva}

\begin{tabular}{|c|c|c|}
\hline & Média & Desvio-padrão \\
\hline Engajamento & 4,29 & 0,72 \\
\hline Eu fico completamente envolvido com o meu trabalho & 4,46 & 0,83 \\
\hline $\begin{array}{l}\text { Eu penso em melhorar a maneira como faço meu trabalho, mesmo quando não } \\
\text { estou trabalhando }\end{array}$ & 4,41 & 0,86 \\
\hline $\begin{array}{l}\text { Eu converso com meus colegas sobre como melhorar a maneira que realizo meu } \\
\text { trabalho }\end{array}$ & 4,13 & 0,99 \\
\hline $\begin{array}{l}\text { Eu converso com meus colegas sobre como melhorar a maneira como a equipe ou } \\
\text { departamento trabalha }\end{array}$ & 4,14 & 1,01 \\
\hline Liderança empoderadora & 3,80 & 0,99 \\
\hline $\begin{array}{l}\text { Meu gestor me ajuda a entender a importância do meu trabalho para a eficácia } \\
\text { global da empresa }\end{array}$ & 3,80 & 1,17 \\
\hline $\begin{array}{l}\text { Meu gerente toma muitas decisões junto comigo } \\
\text { Meu gerente solicita a minha opinião sobre decisões que possam me afetar }\end{array}$ & $\begin{array}{l}3,43 \\
3,48\end{array}$ & $\begin{array}{l}1,46 \\
1,44\end{array}$ \\
\hline $\begin{array}{l}\text { Meu gerente acredita na minha capacidade de melhorar mesmo quando cometo } \\
\text { erros }\end{array}$ & 3,95 & 1,13 \\
\hline Meu gerente me permite fazer o meu trabalho a minha maneira & 3,92 & 1,20 \\
\hline $\begin{array}{l}\text { Meu gerente me permite tomar decisões importantes rapidamente para satisfazer } \\
\text { as necessidades dos clientes }\end{array}$ & 4,21 & 1,08 \\
\hline Liderança diretiva & 3,93 & 1,03 \\
\hline $\begin{array}{l}\text { Minha equipe de trabalho considera o seu chefe um líder de respeito e } \\
\text { credibilidade }\end{array}$ & 4,00 & 1,16 \\
\hline $\begin{array}{l}\text { As solicitações e orientações de minha chefia facilitam a realização do meu } \\
\text { trabalho }\end{array}$ & 4,05 & 1,11 \\
\hline Periodicamente recebo de meu chefe avaliações sinceras sobre meu desempenho & 3,68 & 1,40 \\
\hline $\begin{array}{l}\text { Os chefes sabem demonstrar como podemos contribuir com os objetivos da } \\
\text { empresa }\end{array}$ & 3,78 & 1,21 \\
\hline Sou sempre bem atendido quando peço orientações ao meu chefe & 4,11 & 1,07 \\
\hline Tenho confiança naquilo que meu chefe diz & 3,98 & 1,23 \\
\hline
\end{tabular}

Fonte: Pesquisa (2020).

No geral, o construto engajamento a média de $(4,29)$, liderança diretiva $(3,93)$ e liderança empoderadora $(3,80)$, os desvios-padrões apresentam resultados semelhantes. Tanto em liderança empoderadora quanto em diretiva moderado coeficiente de variação, com assertivas variando de $30 \%$ a $40 \%$. Na categoria engajamento, os respondentes apontaram que ficar completamente envolvido com o meu trabalho foi a afirmativa de maior concordância $(4,46)$, seguida por pensar em melhorar a maneira como faz o 
trabalho, mesmo quando não estão trabalhando $(4,41)$. A assertiva de menor média foi sobre conversar com os colegas sobre como melhorar a maneira que realiza o trabalho $(4,13)$, mesmo assim com dentro da escala de concordância mais favorável.

Por sua vez, em liderança empoderadora as duas assertivas de maiores médias foram sobre a a liderança permitir tomar decisões importantes rapidamente para satisfazer as necessidades dos clientes (4,21) e acreditar na capacidade dos funcionários de melhorar mesmo quando cometem erros $(3,95)$. Por outro lado, a percepção mais negativa foi sobre os gerentes tomarem decisões junto com os funcionários $(3,43)$. Já no estilo de liderança diretiva ser sempre bem atendido quando pede orientações ao chefe $(4,11)$ e as solicitações e orientações facilitarem a realização do trabalho $(4,05)$ merecem destaque positivo. A afirmativa de menor valor foi relacionada ao funcionário receber periodicamente avaliações sinceras sobre seu desempenho $(3,68)$.

Esses resultados podem indicar o impacto do perfil da amostra, por constar de metade pessoas que esperam abrir o próprio negócio ou se tornar gestor da empresa e um terço deles veem o emprego atual como fonte de aprendizado para isso ocorrer, o que pode favorecer a percepção dos respondentes.

Ao relacionarmos os estilos de liderança empoderadora, diretiva e engajamento, constatamos moderada correlação positiva de Pearson entre liderança empoderadora e engajamento $(\mathrm{r}=0,53 ; \mathrm{p}<0,01)$ e entre a liderança diretiva e o engajamento $(r=0,48 ; p$ $<0,01)$. Houve forte correlação positiva entre liderança empoderadora e diretiva $(\mathrm{r}=0,71 ; \mathrm{p}<0,01)$. Estes resultados confirmam as hipóteses 1 e 3, ou seja, há relação entre o estilo de liderança empoderadora e diretiva com o engajamento dos funcionários do setor de foodservice, porém, moderadamente.

As variáveis independentes referentes ao tempo de trabalho no setor de foodservice e o cargo do respondente foram as variáveis com significante influência sobre as variáveis dependentes. As demais variáveis independentes não apresentaram diferença significativa sobre elas, ou seja, apresentaram a estatística $\mathrm{T}$ com significância maior que $(\mathrm{p}>0,5)$. 
Banderó, F. A., Silva, R. C., Padilha Filho, M. R. C., Oliveira, P. S. G., \& Alves, C. A. (2021, set./dez.). A relação entre liderança e o engajamento dos profissionais no segmento de serviços de alimentação em Bares e Restaurantes (foodservice)

Tabela 2.

Teste de Levene Para Igualdade de Variâncias e Teste T Para Igualdade de Médias (Tempo no Setor x Engajamento) (Tempo no Setor x Liderança Empoderada) (Tempo no Setor x Liderança Diretiva)

\begin{tabular}{|c|c|c|c|c|c|c|}
\hline & \multicolumn{2}{|c|}{$\begin{array}{l}\text { Teste de Levene } \\
\text { para igualdade de } \\
\text { variâncias }\end{array}$} & \multicolumn{4}{|c|}{ Teste $\mathbf{T}$ para igualdade de médias } \\
\hline & $\mathrm{Z}$ & Sig. & $\mathrm{T}$ & $\begin{array}{c}\text { Sig. } \\
(2 \text { extremidades })\end{array}$ & $\begin{array}{l}\text { Diferença } \\
\text { de média }\end{array}$ & $\begin{array}{c}\text { Erro padrão } \\
\text { de } \\
\text { diferença }\end{array}$ \\
\hline Engajamento & 0,27 & 0,60 & $-1,90$ & 0,05 & $-0,32$ & 0,16 \\
\hline $\begin{array}{l}\text { Liderança } \\
\text { empoderadora }\end{array}$ & 1,38 & 0,24 & $-1,38$ & 0,17 & $-0,31$ & 0,22 \\
\hline $\begin{array}{l}\text { Liderança } \\
\text { diretiva }\end{array}$ & 4,07 & 0,06 & $-0,45$ & 0,65 & $-0,10$ & 0,23 \\
\hline
\end{tabular}

Fonte: Pesquisa (2020).

A variável tempo de trabalho no setor de foodservice apresentou diferenças em engajamento, o que sinalizou que profissionais com mais de 5 anos de trabalho demonstram maior grau de engajamento $(4,40)$ do que os demais com mais tempo $(4,08)$, portanto, a hipótese 5 foi comprovada.

Os resultados refletem maior presença e imersão no trabalho em profissionais com menos tempo de empresa. Ao perceberem pouco suporte para o desenvolvimento de suas carreiras ao longo do tempo, os respondentes mais experientes permitem-nos supor a menor disposição para contribuir com esforço intelectual, emocional e estabelecer conexões significativas com os outros Rees, Alfes e Gatenby, (2013).

\section{Tabela 3.}

Teste de Levene Para Igualdade de Variâncias e Teste T Para Igualdade de Médias (Cargo x Engajamento) (Cargo x Liderança Empoderada) (Cargo x Liderança Diretiva)

\begin{tabular}{|c|c|c|c|c|c|c|}
\hline & \multicolumn{2}{|c|}{$\begin{array}{c}\text { Teste de Levene para } \\
\text { igualdade de } \\
\text { variâncias }\end{array}$} & \multicolumn{4}{|c|}{ Teste T para igualdade de médias } \\
\hline & $\mathrm{Z}$ & Sig. & $\mathrm{T}$ & $\begin{array}{c}\text { Sig. } \\
(2 \text { extremidades })\end{array}$ & $\begin{array}{l}\text { Diferença } \\
\text { de média }\end{array}$ & $\begin{array}{c}\text { Erro padrão } \\
\text { de } \\
\text { diferença }\end{array}$ \\
\hline Engajamento & 5,29 & 0,06 & 3,22 & 0,00 & 0,53 & 0,18 \\
\hline $\begin{array}{l}\text { Liderança } \\
\text { empoderadora }\end{array}$ & 0,36 & 0,61 & 2,58 & 0,01 & 0,59 & 0,22 \\
\hline $\begin{array}{l}\text { Liderança } \\
\text { diretiva }\end{array}$ & 2,31 & 0,13 & 0,84 & 0,40 & 0,21 & 0,24 \\
\hline
\end{tabular}


Fonte: Pesquisa (2020).

A hipótese 2 foi parcialmente confirmada, pois não existem diferenças no impacto do tempo no setor na percepção da liderança empoderadora, todavia, quando consideramos o cargo do respondente houve significante diferença (Chaman et al., 2021; Park et al., 2019). Quem possuía cargos de gestão apresentava maiores médias $(3,94)$ do que os demais funcionários $(3,34)$.

Como o empoderamento envolve o deslocamento de poder de tomada de decisões de líderes para seus liderados, podem ocorrer resistências ou até mesmo choque cultural numa empresa do setor de bares e restaurantes, geralmente, conduzida por gestão familiar e com a vigência de cultura organizacional mais rígida e tradicionalista (Abujudeh, 2019; Miško et al., 2021; Mitonga-Monga, 2020; Nunes \& Pinheiro, 2010; Park et al., 2019). Todavia, é possível supor que os gestores percebem um movimento de deslocamento de poder no ambiente de trabalho. Contudo, a hipótese 4 foi rejeitada, pois não foi comprovada diferença significativa na percepção da liderança diretiva, conforme o perfil e expectativas do profissional.

Por fim, constamos a relação positiva entre os estilos de liderança empoderadora e diretiva e o engajamento. $\mathrm{O}$ ambiente de trabalho dos estabelecimentos de alimentos e bebidas (Bares e Restaurantes) talvez seja um dos mais desafiadores para um gestor, portanto, saber conduzir adequadamente cada estilo pode ser a fator crucial para obter engajamento, levando-se em conta a escassez de suporte de práticas formais $\mathrm{e}$ estruturadas de gestão de pessoa. Ser ao mesmo tempo um líder diretivo para pessoas que demandam maior acompanhamento e mais empoderador em momentos oportunos para estimular o aprendizado e vislumbrar oportunidades de carreira podem ser a resposta para influenciar positivamente o comportamento humano em empresas de alimentos e bebidas (Bares e Restaurantes).

\section{Conclusões e contribuiçãa}

O foco principal deste artigo foi o de relacionar o engajamento de colaboradores no segmento de alimentos e bebidas (Bares e Restaurantes), com os estilos de lideranças empoderadora e diretiva, a fim de contribuir com a gestão de pessoas no setor de alimentos e bebidas (Park et al., 2019; SangWoo Hahm, 2020). Nesse sentido, o estudo buscou contribuir com o segmento e 
Banderó, F. A., Silva, R. C., Padilha Filho, M. R. C., Oliveira, P. S. G., \& Alves, C. A. (2021, set./dez.). A relação entre liderança e o engajamento dos profissionais no segmento de serviços de alimentação em Bares e Restaurantes (foodservice)

estimular o interesse dos profissionais sobre questões relacionados à gestão de pessoas, originando distintas visões sobre como liderar e engajar num setor carente de iniciativas estruturadas de gestão de pessoas e culturas organizacionais mais engessadas.

Conclui-se que a liderança é um processo complexo, que implica o consentimento na relação entre líderes e liderados para o alcance de metas organizacionais. Foi verificada a conexão entre os estilos de liderança empoderadora e diretiva e o engajamento (Park et al., 2019; SangWoo Hahm, 2020). Cabe destacar que a liderança empoderadora, obteve maior correlação com o engajamento dos colaboradores, porém, para compreender este resultado é preciso considerar o cargo do respondente.

Por último, entre as limitações observou-se o número restrito de respondentes, e o perfil de amostra com a lacuna de respondentes de diferentes faixas etárias e níveis de qualificação profissional. Cerca de metade dos respondentes pretendiam montar seu próprio negócio e visualizavam os atuais empregos apenas como forma de obtenção de experiência. Portando, os resultados não podem ser generalizados a todo o setor de alimentos e bebidas.

\section{Referências}

Abrasel. (2021). Abrasel. Abrasel. https://abrasel.com.br/abrasel/

Abujudeh, S. (2019). The Role of Human Resource Management in Employees' Job Satisfaction and Organizational Commitment. SEA: Practical Application of Science, 7(2), 137-145.

Babbie, E. (1999). Métodos de pesquisas de survey. Ed. da UFMG. Google-Books-ID: n16gZwEACAAJ

BANDERÓ, F.A., M.R.C., P. F., DA SILVA, R.D.G.C., OLIVEIRA, P.S.G, \& ALVES, C.A. (2020). A Relação entre Liderança e o Engajamento dos Profissionais no Segmento de Foodservice. Anais do XXIII Semead. Semead - Seminários de Pesquisa em Administração, FEA-USP.

Barreto, L. M. T. da S., Kishore, A., Reis, G. G., Baptista, L. L., \& Medeiros, C. A. F. (2013). Cultura organizacional e liderança: Uma relação possível? Revista de Administração, 48(1), 34-52. https://doi.org/10.5700/rausp107 2

Bass, B. M., Avolio, B. J., Jung, D. I., \& Berson, Y. (2003). Predicting unit performance by assessing transformational and transactional leadership. Journal of Applied Psychology, 88(2), 207-218. https://doi.org/10.1037/00219010.88.2.207 
Benedetti Chammas, C., \& da Costa Hernandez, J. M. (2019). Comparing transformational and instrumental leadership: The influence of different leadership styles on individual employee and financial performance in Brazilian startups. Revista de Administração e Inovação - RAI, 16(2), 143-160. https://doi.org/10.1108/INMR08-2018-0064

CAGED. (2021). Cadastro Geral de Empregados e Desempregados (CAGED) - Portal do Fundo de Amparo ao Trabalhador. https://portalfat.mte.gov.br/progr amas-e-acoes-2/caged-3/

Chaman, S., Zulfiqar, S., Shaheen, S., \& Saleem, S. (2021). Leadership styles and employee knowledge sharing: Exploring the mediating role of introjected motivation. PloS one, 16(9), e0257174. https://doi.org/10.1371/journal.p one. 0257174

Creswell, J. W., \& Clark, V. L. P. (2013). Pesquisa de Métodos Mistos ( $2^{\circ}$ edição). Penso.

Da Silva, E. P., \& Dos-Reis, M. C. A. (2016). OS ESTILOS DE LIDERANÇA E SUA INFLUENCIA NO DESENVOLVIMENTO DAS ORGANIZAÇÕES. 7(2), 44-56.

da Silva, P. L., Nunes, S. C., \& Andrade, D. F. (2019). Managers' leadership style and the commitment of their team members: Associating concepts in search of possible relations. Revista Brasileira de Gestão de Negócios, 21(2), 291-311. https://doi.org/10.7819/rbgn.v21 i 2.3975
Dallabona, L. F., Silva, D. M. D. A., \& Lavarda, C. E. F. (2019). Variáveis contingenciais, estilos de liderança e folga organizacional predominantes em uma indústria têxtil de Santa Catarina Variable contingencies, leadership styles and organizational slack predominant in a Santa Catarina textile industry. Revista Capital Científico - Eletrônica (RCCe) ISSN 2177-4153, 17(1), 21-41.

Granez, C. R. L., Bortoluzzi, C. A. P., \& Bissani, N. (2016). O PERFIL DAS LIDERANÇAS COMO FATOR DE SUCESSO NAS ORGANIZAÇÕES. 17.

Jr, J. F. H., Black, W. C., Babin, B. J., Anderson, R. E., Tatham, R. L., Gouvêa, M. A., \& Sant'Anna, A. S. (2009). Análise Multivariada de Dados (6 $6^{\mathrm{a}}$ edição). Bookman.

Junior, A. P. (2014). LIDERANÇA: EVOLUÇÃO DAS SUAS PRINCIPAIS ABORDAGENS TEÓRICAS. 13.

Kerlinger, F. N. (1988). Metodologia da Pesquisa em Ciências Sociais. Um Tratamento Conceitual (Edição: $8^{\mathrm{a}}$, Edição: $8^{\mathrm{a}}$ ) [Computer software]. EPU.

Knight, C., Patterson, M., \& Dawson, J. (2017). Building work engagement: A systematic review and meta-analysis investigating the effectiveness of work engagement interventions. Journal of Organizational Behavior, 38(6), 792-812. https://doi.org/10.1002/job.2167

Kraemer, F. B., \& Aguiar, O. B. de. (2009). Gestão de competências 
Banderó, F. A., Silva, R. C., Padilha Filho, M. R. C., Oliveira, P. S. G., \& Alves, C. A. (2021, set./dez.). A relação entre liderança e o engajamento dos profissionais no segmento de serviços de alimentação em Bares e Restaurantes (foodservice)

e qualificação profissional no segmento da alimentação coletiva. Revista de Nutrição, 22, 609-619.

https://doi.org/10.1590/S141552732009000500002

Leite, Y. V. P., Siqueira, E. S., Binotto, E., \& Salazar, V. S. (2013). A LIDERANÇA ESTRATÉGICA COMO FORMA DE EXERCÍCIO DE PODER DESPERSONALIZADO. Gestão \& Planejamento - G\&P, 14(2). https://doi.org/10.53760/g\&p

Malhotra, N. K., \& Menezes, R. S. de. (2019). Pesquisa de Marketing: Uma Orientação Aplicada (7 $7^{\mathrm{a}}$ edição). Bookman.

Miško, D., Vagaš, M., Birknerová, Z., Tej, J., \& Benková, E. (2021). Organizational Commitment of Human Resources in the Context of Leadership Styles in the Organization. TEM Journal, 10(3), 1058-1063. https://doi.org/10.18421/TEM10 3-08

Mitonga-Monga, J. (2020). Social exchange influences on ethical leadership and employee commitment in a developing country setting. Journal of Psychology in Africa, 30(6), 485-491. https://doi.org/10.1080/1433023 7.2020 .1842587

Moon, J. (2021). Effect of Emotional Intelligence and Leadership Styles on Risk Intelligent Decision Making and Risk Management. Journal of Engineering, Project \& Production Management, 11(1),
71-81. https://doi.org/10.2478/jeppm2021-0008

Nunes, A. J. S., \& Pinheiro, P. G. (2010). TEORIA CONTINGENCIAL DE FIEDLER: APLICAÇÃO PRÁCTICA DA ESCALA LEAST PREFERED CO-WORKER (LPC). 16.

Park, S., Han, S. J., Hwang, S. J., \& Park, C. K. (2019). Comparison of leadership styles in Confucian Asian countries. Human Resource Development International, 22(1), 91-100. https://doi.org/10.1080/1367886 8.2018.1425587

Pestana, M. H., \& Gageiro, J. N. (2009). Análise Categórica, Árvores de Decisão e Análise de Conteúdo. Em Ciências Sociais e da Saúde (1 ${ }^{a}$ edição). Lidel.

Pestana, M. H., \& Gageiro, J. N. (2014). Análise de Dados Para Ciências Sociais-A Complementaridade do Spss. Sílabo.

Qadir, K. H., \& Yeşiltaş, M. (2020). Effect of leadership styles on organizational commitment and performance in small- and medium-sized enterprises in Iraqi Kurdistan. Social Behavior \& Personality: an international journal, 48(9), 1-12.

Rees, C., Alfes, K., \& Gatenby, M. (2013). Employee voice and engagement: Connections and consequences. The International Journal of Human Resource Management, 24(14), 27802798. 
https://doi.org/10.1080/0958519 2.2013 .763843

Rego, P., Lopes, M. P., \& Nascimento, J. L. (2016). Authentic Leadership and Organizational Commitment: The Mediating Role of Positive Psychological Capital. Journal of Industrial Engineering \& Management, 19(1), 129-151. https://doi.org/10.3926/jiem.154 0

Rezende Oliveira, R., Goncalves, C. A., \& Cordeiro Martins, H. (2017). Desempenho Organizacional: Integração do Modelo Valor, Raridade, Imitabilidade e Organização com a Gestão de Projetos. Contabilidade, Gestão e Governança, 20(2), 252-275. https://doi.org/10.21714/19843925 2017v20n2a5

Rodrigues, A. D. O., Ferreira, M. C., \& Mourão, L. (2013). O Fenômeno da Liderança: Uma revisão das principais teorias. Fragmentos de Cultura, 23(4), 587. https://doi.org/10.18224/frag.v2 $3 \mathrm{i} 4.3556$

Rodrigues, A. de O., Ferreira, M. C., \& Mourão, L. (2013). O Fenômeno da Liderança: Uma revisão das principais teorias. Revista Fragmentos de Cultura - Revista Interdisciplinar de Ciências Humanas, 23(4), 587-601. https://doi.org/10.18224/frag.v2 $3 \mathrm{i} 4.3556$

SangWoo Hahm. (2020). A Study of the Roles of Leadership Styles and Attitudes with Social Responsibility for the 4th Industrial Revolution. KSII Transactions on Internet \& Information Systems, 14(2),
789-806.

https://doi.org/10.3837/tiis.2020. 02.018

Schley, J., Zampier, M. A., Stefano, S. R., \& Kuhl, M. R. (2015). Estilos de liderança: Um estudo sobre a percepção dos funcionários de um supermercado da mesorregião central do Paraná. Revista de Administração IMED, 5(2), 139-152. https://doi.org/10.18256/22377956/raimed.v5n2p139-152

Silva, R. C. da, Dutra, J. S., Veloso, E. F. R., Fischer, A. L., \& Trevisan, L. N. (2015). Generational perceptions and their influences on organizational commitment. Management Research: The Journal of the Iberoamerican Academy of Management, 13(1), 5-30. https://doi.org/10.1108/MRJIA M-12-2013-0537

Sungu, L. J., Weng, Q. (Derek), \& Xu, X. (2019). Organizational commitment and job performance: Examining the moderating roles of occupational commitment and transformational leadership. International Journal of Selection \& Assessment, 27(3), 280-290. https://doi.org/10.1111/ijsa.1225 6 